Acta Universitatis Sapientiae, Philologica, 7, 2 (2015) 21-33

DOI: 10.1515/ausp-2015-0044

\title{
Travelling among Languages - Comparing Language Learning Beliefs of Learners at Home Versus Migrant or Immigrant Workers
}

\author{
Enikő BIRÓ \\ Babeş-Bolyai University (Cluj Napoca, Romania) \\ Department of Modern Languages \\ eniko.biro@lingua.ubbcluj.ro
}

\begin{abstract}
The paper presents a qualitative approach to language learning beliefs while analysing case studies in detail to offer significant insight into these beliefs and language learning as well. A number of studies have shown that the belief system of language learners plays a decisive role in their success and failure in language learning (Bernat \& Gvozdenko 2005; Horwitz 2008). The research presents the content analysis of interviews with bilingual participants. Interviews were carried out with migrant workers, other interviews with bilingual students in Romania, as well as online interviews with immigrant workers in the EU. The paper explores different beliefs learners hold regarding learning languages. By comparing migrant workers' and students' beliefs the complexity of positive and negative beliefs are presented. These may change due to previous and current language learning experiences, cultural-, social-, and educational background, personality traits, etc. The result of the qualitative analysis has shown that beliefs are linked to the particular language placed in a socialcultural dimension; the same beliefs may not be possible to be transferred to the next language being learnt, individual differences in beliefs regarding learning languages and their dynamic change in different language learning processes are investigated in details.
\end{abstract}

Keywords: language learning beliefs, interview, bilinguals, dominant bilingualism

\section{Introduction. A guidebook to the travel}

Attitudes and beliefs play an important role in directing human behaviour, therefore in directing the process of learning languages as well. Approaching language learning beliefs creates the need to determine what the terms bilingualism and bilinguals refer to in the present research. Bilingualism refers to a definite 
ability to use two languages in everyday life. It has become common truth that bilingualism is a natural state of being and is on rise in many parts of the world. Contact between two or more languages is typical in regions of many countries. Bilinguals can learn two languages from birth, i.e. simultaneous bilinguals, and learn a first language followed by a second language, i.e. sequential bilinguals. It has been proved that there are advantages for simultaneous bilinguals relative to sequential bilinguals. They tend to have better accents, larger vocabulary, and higher grammatical proficiency. However, bilingual exposure does not necessarily translate to being a bilingual who is able to understand and speak both languages fluently, claimed by Kiss (1995: 35):

The Hungarians living outside the borders of Hungary - with a few exceptions - can be characterized by a lower or higher degree of bilingualism. There are some who understand the official language of the country, there are others who speak the official language at an elementary, intermediate or advanced level, and there are some who can speak their mother tongue and the second language equally well. ${ }^{1}$

Throughout this paper, the term first language (L1) is used to refer to Hungarian, as a language 'best known and/or most used' by the speakers in question, also called 'mother tongue' and contrasted with the second language (L2) (SkutnabbKangas \& McCarty 2008: 6). The term 'second language' refers to Romanian as the official language used in everyday life situations and within academic and official environments. As the participants of this study are at different levels of bilingualism, the concept of individual bilingualism as defined by Skutnabb-Kangas \& McCarty (2008: 4-5) is used to indicate different levels of proficiency. Individual bilingualism refers to the use of two or more languages by an individual. Individual bilingualism does not necessarily comply with the implementation of a 'bilingual' language policy, which presents its unsatisfactory outcomes concerning the Hungarian-Romanian bilinguals, and there is a high level of uncertainty even in the use of terminology (Tódor 2008). It is well known that language educational policies are 'mechanisms to create de facto language practices in educational institutions' used by authorities to manipulate language policies. Consequently, all the components of language policies, including decisions referring to mother tongues, or which language(s) to learn and teach in schools (including second language for ethnic minorities) are holders of language ideologies (Shohamy 2006: 76-77). Besides these ideologies, the members of a speech community share a set of beliefs about appropriate language practices, they assign prestige to various aspects of language (Spolsky 2004). These belief systems of language learners play a decisive role in their success and failure 
in language learning; studies have revealed that language learners' beliefs about their own capacity and personal models of their own processes are much more important than universally accepted theories of learning, and some psychometric measures or individual difference factors such intelligence or aptitude (Bernat 2008). Belief systems are influential; they raise learners' consciousness and shape their attitude towards language learning, learning strategies and policies. The language learners, being at any level of bilingualism, have beliefs about the languages learnt, their language aptitude and learning strategies. However, some beliefs may have a facilitative effect on learning, while others can hinder it. Supportive beliefs help to overcome problems and thus sustain motivation, while unrealistic beliefs can lead to decreased motivation, increased frustration, and even anxiety (Horwitz 2001). Therefore, understanding learners' beliefs is essential. Raising the awareness of learners' beliefs has become central to language pedagogy, knowing that beliefs shape the path learners hold about language and language learning process and product.

The paper has been dedicated to explore what beliefs are related to language learning processes and it has aimed as research objective to present differences which can be identified regarding learning two or more languages. The interviews revealed the representations of these beliefs and the dynamic characteristics of them.

\section{Interviews as mirrors of the travel}

While quantitative research methods provide clarity and precision throughout the use of well-designed questionnaires and descriptive statistics, can include a large number of respondents and afford them anonymity, they do have limitations. For example, the beliefs profiled in survey studies are generally limited to those identified by the researcher and therefore might not be representative of all the beliefs learners hold about language learning. There is also potential for misinterpretation of questionnaire items. They are less complex, focus-oriented, and context-centred. Furthermore, some argue that a construct, as intellectually and affectively complex and rich as is one's personal belief system, is difficult to capture by people's responses to a set of normative statements (Weinstein 1994). Empirical approaches using the sociocultural perspective typically employ qualitative research methods. Studies are usually small-scale and employ in-depth, descriptive and interpretive analyses. They offer a rich insight into the systems of beliefs and individual language learning experiences. They can include a variety of data collection methods such as interview techniques, journal or diary entries, as well as classroom observations. However, the limitations of such studies are reflected by researcher's selectivity of data, a degree of interpretive subjectivity, 
and context-specificity resulting in lack of application to broader SLA contexts (Bernat \& Gvozdenko 2005). It is important to note that collecting data through qualitative research may offer further insights into language learning beliefs, how they work in the learners' minds.

Language learning beliefs were identified and classified by different researchers: Wenden (1986), Horwitz (1987), Cotterall (1995), just to name a few of them. A reliable research tool with good psychometric qualities, the Beliefs about Language Learning Inventory (BALLI) questionnaire, was created by Horwitz (1987), to assess students' beliefs about language learning in five major areas: (1) foreign language aptitude, (2) the difficulty of language learning, (3) the nature of language learning, (4) learning and communication strategies, and (5) motivations and expectations. Research has shown that beliefs about learning are important part of knowledge (Arnold 1999), and they develop early in elementary and secondary school children (Williams 1994). Williams also added that:

Language, after all, belongs to a person's whole social being: it is part of one's identity, and is used to convey this identity to other people. The learning of a foreign language involves far more than simply learning skills, or a system of rules or a grammar, it involves an alteration in self-image, the adoption of new social and cultural behaviors and ways of being, and therefore has a significant impact on the social nature of the learner (ibid., 77).

The social and family background is among the various factors which influence learner beliefs (Dias 2000), as well as the cultural background (Alexander \& Dochy 1994). Furthermore, classroom/social peers (Arnold 1999) and the interpretations of prior repetitive experiences (Little, Singleton \& Silvius 1984, Kern 1995) may have an impact on these beliefs. It is suggested that beliefs are intertwined with factors such as self-concept and identity, self-efficacy, personality and other individual differences (Epstein 1990). However, it is even more important to find out what factors may change them. The stable or static nature of beliefs is among the most central claims of the mainstream approach. On the other hand, Rust (1994) describes beliefs as socially-constructed representation systems used to interpret and act upon the world. Beliefs are seen by him as fluid and dynamic, not stable entities within the individual and they change and develop over time. This dynamic characteristic can be traced by comparing learners' beliefs in case of two or more different language learning processes (Romanian and English, or other languages).

In our research, the interview transcripts provide the texts that serve as a domain of analysis. After a selective reduction of the text to categories the focus was placed on matching them with the research questions, being representative of the view of all of the interviewees. In other words, the present paper presents 
opinions that occurred in all of the interviews and, as such, the excerpts quoted are representative of the opinion of all of the interviewees. Content analysis is based on the meaning unit, that is, the constellation of words or statements that relate to the same central meaning, related to each other through their content and context. The empirical focus is on the qualitative content of bilinguals' language learning beliefs and learning strategies. Language learning beliefs, as qualitative variables, shape the learners' engagement in language learning process positively or negatively. It is a method to identify belief structures of bilinguals' language learning process.

\section{The variety of the travellers}

The travel among languages varies according to the travellers. There were 19 bilingual students at two universities, where interviews were carried out between May-June, 2014 and February-March, 2015. 14 participants were students at the Babeş-Bolyai University (Sfântu Gheorghe), while 5 participants belonged to the Sapientia Hungarian University of Transylvania (Miercurea Ciuc). The second group of participants were migrant workers born in Transylvania; the interviews were conducted in Transylvania in $2012^{2}$ (the total number of the interviews was 28; however, only 18 met the aim of the present paper). The interviewees were all migrant workers, formerly working in the EU and the USA. The third group of interviewees consisted of 4 Hungarian ethnic immigrants, bilinguals as well, permanently living abroad (Austria, Italy and Israel). The participants of the study are all bilinguals, their L1 is Hungarian and L2 is Romanian. Among the participants there were 3 balanced bilinguals (coming from mixed families). Besides speaking Hungarian as their mother tongue and Romanian as their second language, they all speak one or more other languages, e.g. English, German, Italian, etc.

The travel among languages, i.e. using various languages, meets the dilemmas of bilingualism, multilingualism and intercultural skills. In the two counties where the Hungarians form the majority of the population, children meet the second language around age 6 or 7 , which is the school age. They can be characterized by sequential, dominant bilingualism. Although Romanian is present in their everyday lives, this influence is little and depends on many contextual factors. The informal way of learning the language is missed, it results in hard times to improve second language proficiency later. Therefore, there is a need to 'travel' to the land of second language (educational, economic, social, personal needs), for a higher proficiency in Romanian. Varying levels of bilingualism is a fact among

2 Migration and economic culture - research project, 2011-2012, financed by the Hungarian Academy of Sciences. Project leader: Angella Sorbán. 
the Hungarian ethnic minority. Considering the advantages of bilinguals and multilinguals it is worth mentioning that bilingual and multilingual individuals are experienced learners and the state of being bilingual influences third or fourth, and additional language learning processes. They are more open towards the third/ fourth languages. The strategies of learning these two languages are transferable, the travel is possible between languages (Biró 2012). Still, multilingualism remains a label for them - as only high language proficiency fosters acquisition of further languages. They also meet their intercultural dilemmas. Acquiring intercultural skill refers to the development of those skills which enable language learners to understand the target culture and cultural conventions. It also refers to increased learners' awareness towards the target culture and to their own, sensitizing them to cultural diversity. In the case of dominant bilinguals there is a gap between their own and second language culture. However, immigrant and migrant workers are actually experiencing the other cultures, comparing them, demonstrating constant learning attitude towards intercultural skills:

It was so odd when I arrived in Switzerland, everything in precise order, even the stables, nothing like at home [in Romania](...) (participant from Odorheiu Secuiesc, 32, working in Switzerland)

It is matter of economic challenge for migrant workers to survive there and to achieve their initial personal goals. Within this context language learning mainly depends on the language learner's attitude (shaped by the context, by the home country, by previous attitudes, prejudices, etc.), on his or her motivation (instrumental motivation mostly - surviving at a workplace), on their language learning beliefs (shaped by previous language learning experiences, in our case Romanian language mainly). Beliefs regarding language learner abilities are related to the circumstances, to the context (being in a native speaking environment). Participants reported on friendly environments which helped their learning, support from families or from the community and practice, the use of language helped them a lot; besides, travelling, meeting other cultures strengthened flexibility and acceptance towards languages, thus developing their intercultural skills.

The results of the research with the help of semi-structured interviews show what beliefs are related to their language learning processes and what differences they can mention regarding learning the two or more languages. These factors were identified during the content analysis of 41 interviews in total. 
Table 1. Participants, age, gender and languages learnt

\begin{tabular}{llll}
\hline Gender & Age range & \multicolumn{2}{c}{ Languages learnt (number) } \\
\cline { 3 - 4 } & & students & migrant workers and immigrants \\
\hline 18 female & $19-41$ & $\begin{array}{l}\text { Romanian (18), English (18), } \\
\text { German (12), French (6), } \\
\text { Spanish (1) }\end{array}$ & $\begin{array}{l}\text { Romanian (18), English (18), German (16), } \\
\text { French (2), Spanish (4), Italian (5), Hebrew (1) }\end{array}$ \\
\hline 23 male & $19-69$ & $\begin{array}{l}\text { Romanian (23), English (23), } \\
\text { German (17), French (5) }\end{array}$ & $\begin{array}{l}\text { Romanian (23), English (23), German (20), } \\
\text { French (3), Spanish (5), Italian (4), Danish } \\
\end{array}$ \\
& & & (3), Norwegian (1), Swedish (3), Croatian (1)
\end{tabular}

The interviewees' profile reveals some personal data, as gender, age, family background (3 coming from a mixed family - Hungarian mother, Romanian father, the rest from Hungarian families), language of instruction in kindergarten and school, as well as their language proficiency regarding both languages: Romanian and English. Their language proficiency was based on self-assessment. Second language speakers believe in higher second language proficiency than their actual level of proficiency as it provides them with functional communication within the context (Dörnyei 2001). The student participants were usually not satisfied with their Romanian proficiency, the overall underestimation of it shows their unstable feelings, but also the wish to constantly improve it in the future. They face their lack of knowledge each day; therefore, they are able to assess their own skills in a very detailed way. Migrant workers, coming from counties where the majority of the population is formed by the Romanian ethnicity, are generally satisfied with their Romanian language knowledge; they consider themselves as balanced bilinguals, able to use the second language in any circumstances. The overall satisfaction of their English knowledge obviously comes from overestimation, their beliefs of their English knowledge are mostly positive. Migrant and immigrant workers speak a wider variety of languages compared to the number of languages students speak due to their stay abroad in different countries, although being able to apply the learnt languages in their daily lives does not necessarily mean that they all have become proficient speakers of that particular language.

\section{Comparing positive beliefs of students and migrant/ immigrant workers}

By comparing positive beliefs of the participants regarding learning Romanian and learning other languages the most striking difference could be observed between the beliefs of dominant bilinguals and balanced bilinguals. Students generally reported on family support when it came to language learning, especially regarding Romanian language. The members of the Hungarian minority 
are eager to learn the official language; however, this willingness is hindered by fear of failure. They expect, they believe that learning Romanian is always difficult, while learning English (or other languages) is assumed to be easier. Learning Romanian, the state language of the country, is a must for all citizens: "Parents made us understand that as Hungarian minority speakers we need to learn Romanian, otherwise we will not be able to prevail"; "...I wanted to speak Romanian so much in that moment..."; "you do not feel inferior then". Knowing other languages is usually providing the students with positive feelings: "it is a good feeling", gives "openness, independence". In the case of balanced bilinguals (students coming from mixed families) learning and speaking Romanian was a simultaneous process: "I have advantages compared to my (Hungarian) friends", as well as learning other languages meant to be easier for them, they expressed their confidence in their language learning skills: "I do not believe that one cannot learn a language!"

Migrant workers reported on different beliefs both regarding learning Romanian and other languages. For dominant bilinguals learning Romanian is linked to the necessity of making a living at home: "It is not a foreign language for me"; "I had to learn it in the army - it was a necessity, needed for survival". Their attitude and beliefs about language learning are practical - they have experienced the advantages of language skills and therefore are more willing to learn languages: "Practice is important", "If you are in need, you learn it fast", "You need to learn words, not grammar.", "I started it by myself, every day I learnt five new words, and when I could not use my copybook then I wrote the words on my palm... And I learnt them. I had a strong will”. Balanced bilinguals (coming from mixed families) among the migrant workers assumed that there is a connection between languages, they were aware of it: "if you already know Romanian the next language is easier", "there is a connection among languages". They are more eager to learn languages, simply because of the practical need of communication: "I wanted to know", confessed one of the participants (she speaks English, Italian and German, understands Spanish); revealing her wish to learn languages simply because she always wanted to be able to communicate with people around her.

As a conclusion, it can be stated that having self-confidence, having a positive belief about their own language learning abilities (foreign language aptitude beliefs), assuming the easiness of a language (the difficulty of language learning beliefs), believing in the necessity of learning the language (the nature of language learning beliefs / motivations and expectations beliefs) all help to acquire a language. Beliefs about learning and communication strategies - the fifth category of language learning beliefs identified by Horwitz (1987) - cover a wide range of strategies, however, practice, communication, learning the vocabulary, reading, watching movies, watching cartoons, playing computer games, singing, language courses and learning grammar are among the top ten. 


\section{Comparing negative beliefs of students and migrant/ immigrant workers}

Negative beliefs mainly refer to learning Romanian by dominant bilinguals. Learning Romanian caused nervousness, anxiety, even lack of self-confidence of the participants: "you were so discouraged", "I had a teacher who gave me bad marks, 'patru' [four, failed], whether I knew or not", "you just do not start from the elementary level, you miss that", "only grammar, we were afraid in the class", "you cannot learn Romanian in a Hungarian village". Romanian is compared with other foreign languages such as English, when interviewees describe their opinion regarding state language teaching methodology. Difficulties were met due to the inappropriate methodology of teaching Romanian, missing informal ways of acquiring the language and experiencing psychological reasons (fear, anxiety, and nervousness). Balanced bilingual students did not mention any problems regarding learning Romanian. In the case of other languages they mainly mentioned difficulties due to the inappropriate methodology of teaching languages or flaws in the system of education. They found learning the grammar of a language difficult, or hard to understand: "I have problems with the English grammar rules"; "I find German language unfriendly" or complained about the educational system: "Frequent change of teachers was a disadvantage".

Migrant workers obviously had more problems with integration into the host community, society, which is reflected in the process of language learning: "You will always stay an immigrant". Their language abilities are narrowed down to certain registers and certain levels of communication within the host community, therefore experiencing lack of knowledge sometimes: "Difficult to learn the dialects". Migrant workers did not report on any negative beliefs concerning Romanian, however, some of them complained about the so-called 'false friends', words looking or sounding similar in two languages, but differing in meaning: "Romanian confused me, words look like Italian but they are not correct in Italian".

Learning a language easily is mainly related to the like (liking the language), having an ear for the language, being motivated. These abilities are generally associated with the English language. It is very important to mention that the speaker might have an ear for English, but not for the Romanian. It means that they distinguish their beliefs according to the learnt languages, unlike language learning strategies these beliefs do not seem to be transferable. Distinguishing two different sets of beliefs explains the successful and unsuccessful acquisition of the two languages: "You cannot learn Romanian in my hometown [majority of the population is Hungarian], it is impossible. (...) I just picked up English, somehow it was 'attached' to me, I 'liked it'" [the same participant]. However, migrant workers rarely report on unsuccessful acquisition of languages, their language learner abilities are strongly connected to the survival in a foreign 
society. They meet anxiety at the beginning of their stay, later on it disappears. Their lower social status and lack of power prescribe cautious behaviour, to cover their lack of language proficiency: "because when I wanted to say something I had a colleague to translate for me, or I talked in English [not German], and if I did not know something I withheld any questions, and did not discuss that issue." Immigrants' and migrant workers' employment opportunities must address the central challenge: acquiring proficiency in their host country's language. Language proficiency is one of the most important determinants of immigrant integration; with greater host language proficiency they earn more and work in more skilled occupations than those with low proficiency. Those who go abroad for a period to live in a native speech community are motivated to find out what this useful knowledge of a language consists of, how they make to linguistically fit the community.

Negative beliefs regarding language learning most certainly hinder the acquisition of a language. These beliefs are deep-rooted, hard to change. The key seems to be the travel itself - working or just simply spending enough time in a native language speaking environment have had obvious and positive outcomes.

\section{Conclusion}

In this paper we have presented some underlying theories of language learners' beliefs followed by the analysis of migrant workers' and students' interviews regarding language learners' beliefs. The qualitative analysis of the interviews in the second part of the paper has hopefully shown two main approaches of studying language learners' beliefs. First of all, we analysed the beliefs learners hold regarding learning the second language, Romanian, and the foreign language, English. Then we explored the differences language learners could mention regarding learning two or more languages. By comparing migrant workers' and students' beliefs we tried to present the complexity of positive and negative beliefs. Beliefs seem not to be stable; they can change due to previous and current language learning experiences, cultural-social-educational background, personality traits, etc. They may vary according to the context: learning a language in a native language speaking community emphasizes different beliefs than a "safe" home environment, hence the over- or underestimation of their own language abilities. Regardless of personality traits, positive beliefs seem to enhance language learning a lot, and the like of the language empowers positive beliefs of the learners' language aptitude - shown by the different language learning processes of the same learner. It seems difficult to transfer positive beliefs regarding learning a certain language to a next language, and negative beliefs do not influence the next language learning process. Whether positive 
beliefs helped them learn a language better or being able to learn a language determined their positive beliefs still remains a question. It seems to be true that learning more languages successfully builds more positive beliefs and balanced bilinguals outstand for these beliefs. The narratives illustrate the differences in this complex system of language learning beliefs and a holistic picture can be gained about language learning.

However, beliefs are linked to the particular language placed in a social-cultural dimension; the same beliefs may not be possible to be transferred to the next language being learnt. Successful language learning includes many influences and we may further analyse the cognitive influences (e.g., knowledge of L1, linguistic analysis capacity, memory), motivational influences (e.g., interest in the L2, L3, value of the L2, L3 to the learner, positive affect toward speakers of the L2, L3), social influences (e.g., opportunities to interact with L2, L3 speakers, access to useful feedback), and instruction (e.g., quantity, quality, design). Separating the social and the individual factors may never lead us to understanding language learning. Pavlenko (2002) mentions a number of issues which deserves further investigations, stating that internal and psychological factors as attitude, motivation or language learning beliefs have clear social origins and are shaped and reshaped by the contexts in which the learners find themselves.

Therefore, the most important finding of the present study is shown by the individual differences of beliefs regarding learning languages and their dynamic change in different language learning processes. Very distinct, even opposite beliefs linked to different languages may direct the language learning behaviour of the participants. The distance between languages seems to matter but not as strongly as one would expect. Participants, who were able to learn English, then Italian, were having hard times learning German.

To sum up, travelling - literally and metaphorically - represents the possibility of change. Travelling on the road of language learning process in order to reach a higher proficiency can turn negative beliefs into positive ones, or spending some time in a native language speaking environment can foster positive changes. Dominant bilinguals have a longer way to go, while balanced bilinguals enjoy a higher self-confidence during their travel. Migrant workers' real world experiences work as a great motivating influence and build a new system of beliefs on their road. 


\section{References}

Alexander, Patricia \& Dochy, Filip. 1994. Adults' views about knowing and believing. In R. Garner, \& P.A. Alexander (eds.), Beliefs about Text and about Instruction with Text, 223-244. Hillsdale, NJ: Erlbaum.

Arnold, Jane. 1999. Affect in Language Learning. Cambridge: Cambridge University Press.

Bernat, Eva, \& Gvozdenko, Inna. 2005. Beliefs about Language Learning: Current Knowledge, Pedagogical Implications, and New Research Directions. TESL-EJ, 9(1): 1-21.

Bernat, Eva. 2008. Beyond Beliefs: Psycho-cognitive, Sociocultural, and Emergent Ecological Approaches to Learner Perceptions in Foreign Language Acquisition. Asian EFL Journal, 10(3): 7-27.

Biró Enikő. 2012. Kétnyelvúek nyelvtanulási stratégiái. [Language Learning Strategies of Bilinguals]. Bolyai Társaság, Kolozsvár: Egyetemi Múhely Kiadó.

Cotterall, Stella. 1995. Readiness for Autonomy: Investigating Learner Beliefs. System 23(2): 195-205.

Dias, Roy. 2000. Lebanese Students' Beliefs about Learning English and French: A Study of University Students in a Multilingual Context. Dissertation Abstracts International. 62 (02), 497 A (UMI No. 3004253).

Dörnyei, Zoltán. 2001. Teaching and Researching Motivation. Harlow: Pearson Education Limited.

Epstein, Seymour. 1990. Cognitive-experiential Self-theory. In L. Pervin (ed.), Handbook of Personality: Theory and Research, 165-192. New York: Guilford Publications, Inc.

Horwitz, Elaine. 1987. Surveying Student Beliefs about Language Learning. In A. Wenden \& J. Rubin (eds.), Learner Strategies in Language Learning, 119-129. Englewood Cliffs, NY: Prentice Hall.

Horwitz, Elaine. 2001. Language Anxiety and Achievement. Annual Review of Applied Linguistics 21: 112-126.

Horwitz, Elaine. 2008. Why Student Beliefs about Language Learning Matter. The Evolution of the Beliefs about Language Learning Inventory. In J. Siskin (ed.), Issues in Language Program Direction, 2-8. American Assoc. of University Supervisors and Coordinators.

Kern, Richard. 1995. Students' and Teachers' Beliefs about Language Learning. Foreign Language Annals 28(1): 71-92.

Kiss, Jenő. 1995. Társadalom és nyelvhasználat. [Society and Language Use.] Budapest: Nemzeti Tankönyvkiadó.

Little, David, Singleton, David, \& Silvius, W. 1984. Learning Second Languages in Ireland: Experience, Attitudes and Needs. Dublin: Trinity College. 
Pavlenko, Aneta. 2002. Poststructuralist Approaches to the Study of Social Factors in Second Language Learning and Use. In Cook, Vivian (ed.), Portraits of the L2 User, 277-302. Clevedon: Multilingual Matters.

Rust, Frances. 1994. The First Year of Teaching. It's Not What They Expected. Teaching and Teacher Education 10: 205-217.

Shohamy, Elana. 2006. Language Policy: Hidden Agendas and New Approaches. London \& New York: Routledge.

Skutnabb-Kangas, Tove \& Teresa L. McCarty. 2008. Bilingual/Immersion Education: What the Research Tells Us. In Cummins, Jim \& Nancy H. Hornberger (eds.), Encyclopedia of Language and Education (5): 3-17. New York: Springer. Spolsky, Bernard. 2004. Language Policy. Cambridge: Cambridge University Press.

Tódor, Erika. 2008. Reperele analitice ale bilingvismului instituțional. [Analytical Aspects of Institutional Bilingualism.] Working Papers in Romanian Minority Studies 10: 1-29. Cluj Napoca: Institutul pentru Studierea Problemelor Minorităților Naționale.

Weinstein, Carol. 1994. A Look to the Future: What We Might Learn from Research on Beliefs. In R. Garner \& P. Alexander (eds.), Beliefs about Text and about Instruction with Text, 295-302. NJ: Lawrence Erlbaum.

Wenden, Anita. 1986. Helping Language Learners Think about Learning. English Language Journal 40(1): 3-12.

Williams, Marion. 1994. Motivation in Foreign and Second Language Learning: An Interactive Perspective. Educational and Child Psychology 11: 77-84. 